\title{
Review
}

\section{A Mitocentric View of Alzheimer's Disease Suggests Multi-Faceted Treatments}

\author{
Gary E. Gibson* and Qingli Shi \\ Weill Cornell Medical College/Burke Medical Research Institute, White Plains, NY, USA
}

Accepted 5 April 2010

\begin{abstract}
Alzheimer's disease (AD) is defined by senile plaques made of amyloid- $\beta$ peptide $(\mathrm{A} \beta)$, neurofibrillary tangles made of hyperphosphorylated tau proteins, and memory deficits. Thus, the events initiating the cascade leading to these end points may be more effective therapeutic targets than treating each facet individually. In the small percentage of cases of AD that are genetic (or animal models that reflect this form of $\mathrm{AD}$ ), the factor initiating $\mathrm{AD}$ is clear (e.g., genetic mutations lead to high $\mathrm{A} \beta_{1-42}$ or hyperphosphorylated tau proteins). In the vast majority of AD cases, the cause is unknown. Substantial evidence now suggests that abnormalities in glucose metabolism/mitochondrial function/oxidative stress (GMO) are an invariant feature of AD and occur at an early stage of the disease process in both genetic and non-genetic forms of AD. Indeed, decreases in brain glucose utilization are diagnostic for AD. Changes in calcium homeostasis also precede clinical manifestations of AD. Abnormal GMO can lead to plaques, tangles, and the calcium abnormalities that accompany AD. Abnormalities in GMO diminish the ability of the brain to adapt. Therapies targeting mitochondria may ameliorate abnormalities in plaques, tangles, calcium homeostasis, and cognition that comprise AD.
\end{abstract}

Keywords: Alzheimer's disease, amyloid, calcium, mitochondria, oxidative stress, neurofibrillary tangles, senile plaques

\section{INTRODUCTION}

Alzheimer's disease (AD) is defined by senile plaques and neurofibrillary tangles and progressive cognitive changes including memory loss. Since these features are the defining characteristics of $\mathrm{AD}$, hypotheses to explain $\mathrm{AD}$ must address what induces the alterations in the processing of amyloid- $\beta$ protein precursor (A $\beta \mathrm{PP})$ that lead to plaque formation and the hyperphosphorylation of tau protein that leads to tangles. Other abnormalities that accompany AD and occur earlier in the disease process are plausible candidates to be upstream events that initiate plaque and tangle formation as well as the cognitive loss. Considerable evidence suggests that the changes in glu-

\footnotetext{
* Correspondence to: Gary E. Gibson, PhD, Department of Neurology and Neuroscience, Weill Cornell Medical College, Burke Medical Research Institute, 785 Mamaroneck Avenue, White Plains, New York 10605, USA. Tel.: +1 914597 2291; Fax: +1 914597 2821; E-mail: ggibson@med.cornell.edu.
}

cose metabolism/mitochondria/oxidative stress (GMO) and calcium homeostasis precede plaques, tangles, and clinical manifestation of $\mathrm{AD}$ in humans and in mouse models. The changes in GMO are plausibly linked in a causative manner to the other abnormalities that define AD. Hence, the early alterations in GMO, which can induce multiple abnormalities, seem like more desirable therapeutic targets than the reversal of the individual facets that may results from abnormalities in GMO.

\section{LINK OF GLUCOSE METABOLISM, MITOCHONDRIAL FUNCTION, AND OXIDATIVE STRESS IN BRAIN FUNCTION}

The brain has a high rate of glucose metabolism and normal brain function depends on glucose metabolism. Even mild reductions in the oxygen or glucose available to the brain diminish brain function including cognition. Novel alternative pathways of glucose utilization and oxygen utilization do not occur in the brain, 
but the coupling of neuronal properties to metabolism is unique. For example, the energy requirements for maintenance of high ionic gradients across membranes and an interaction of metabolism with neurotransmitters are unique to brain. Six neurotransmitters are derived from metabolic pathways and three use molecular oxygen for their synthesis. Furthermore, other aspects of neurotransmission depend upon energy metabolism. For example, any reduction in oxygen availability to the brain diminishes the release of acetylcholine and reduces cholinergic function. Furthermore, neurotransmitter receptors are modified by oxidants. Thus, even mild interruptions in metabolism or oxidative stress alter brain function [1].

Free radicals (compounds with an unpaired electron) or reactive oxygen species (ROS) are a normal part of metabolism. The multiple sources of ROS in cells have been reviewed extensively. The major producer of ROS is thought to be the electron transport chain (ETC) of the mitochondria, particularly complex II and III. Other reactions within the tricarboxylic acid (TCA) cycle including the pyruvate dehydrogenase complex (PDHC), the $\alpha$-ketoglutarate dehydrogenase complex (KGDHC), or malate dehydrogenase (MDH) can also produce free radicals under appropriate conditions [2, 3]. KGDHC may also serve as ROS sensors [4]. Any of the many oxygenases or dehydrogenases in cells are linked to electron transfer and can lead to free radical production. For example, monoamine oxidase can be a major producer of oxidants [5]. Together these reactions represent a high proportion of all reactions in a biological system.

As part of their role in normal metabolism, ROS serve as signaling molecules. Many physiological reactions in all tissues including the ETC are modulated by ROS [6]. ROS can modify neurotransmitter receptors or ion transporters with profound effect on the function of these proteins [1]. ROS communicate between metabolic pathways. For example, production of ROS by the ETC can inactivate KGDHC of the TCA cycle to diminish the production of NADH [7]. ROS produced by monoamine oxidase can also inactivate KGDHC [5]. ROS can even be regulatory within protein complexes. For example, KGDHC consists up of three protein subunits. The third protein of the complex produces ROS that regulates the first protein of the same complex [8].

Oxidative stress occurs under conditions in which production of free radicals or ROS exceeds the ability of the cell or brain to buffer them. Since the ETC chain uses most of the oxygen in neurons, oxidative stress is often associated with the ETC. Any interrup- tion of ETC normal function increases ROS production. For example, in cell systems either increasing or lowering oxygen increases ROS production [2,8]. Impairment of the ETC by a variety of means leads to excess levels of ROS. For example, adding azide to block respiration increases ROS production and inactivates KGDHC [7]. Reducing oxygen and/or glucose to the brain also increases ROS [9]. The excess oxidative stress can modify DNA, RNA, lipids, and proteins. The damaged molecules include those that can be regulated by ROS. For example, KGDHC can be irreversibly inactivated by a variety of oxidants so that recovery is not possible [10]. Thus, oxidative stress diminishes the ability of the brain to adapt.

In vivo studies support the suggestion that interruption of normal metabolism increases free radical production. For example, reducing the activity of the KGDHC and PDHC increases oxidative stress [11]. Mild impairment of metabolism by thiamine deficiency (TD) also increases oxidative stress [12]. ROS also increase in response to hypoglycemia. Increased lipoperoxidation levels are observed before the onset of the hypoglycemic-induced isoelectric period, while 3-nitrotyrosine residues in proteins and nitrotyrosinepositive cells occur with glucose reperfusion. These changes occur only in vulnerable brain regions, suggesting a correlation between oxidative damage and vulnerability to hypoglycemic neuronal death in selective brain regions. The results demonstrate that a pro-oxidant state is promoted in certain brain regions during hypoglycemia and after the glucose reperfusion phase, which may result from the activation of several oxidative stress pathways and may relate to subsequent cell death [13]. Thus, one challenge in unraveling the pathophysiology of $\mathrm{AD}$ is to understand the source of the free radicals that lead to damage in $\mathrm{AD}$.

\section{GLUCOSE METABOLISM/MITOCHONDRIAL FUNCTION/OXIDATIVE STRESS ARE CLOSELY LINKED TO CALCIUM REGULATION}

Calcium, like ROS, is a normal signaling molecule that is closely linked to metabolism. In isolated nerve endings, hypoxia diminishes calcium uptake, but increases cytosolic calcium and diminishes calcium dependent release of acetylcholine [1]. In neurons, intracellular calcium increases in response to depolarization or activation of a variety of receptors. The increased calcium activates numerous calcium dependent 
enzymes in the cytosol, and elevates calcium in the mitochondria and endoplasmic reticulum (ER). The increased calcium in the mitochondria activates a variety of processes, including KGDHC, and can promote ROS production. ROS increase calcium in hypoxic tissues [14]. Calcium in the ER is involved in multiple processes including ER stress, which is involved in cell death processes. Stabilizing the ER calcium can protect against ischemia-induced cell death [15]. The calcium transport systems of the ER are also sensitive to oxidative stress [16].

Calcium, mitochondria, and the ER are closely linked morphologically and functionally. Considerable cross talk of cell death proteins occurs between the ER and mitochondria [17]. Calcium released from the ER can elevate mitochondrial calcium without increasing cytosolic calcium, which suggests a direct morphological link. Double label experiments of ER and mitochondria support this suggestion [18]. Presenilins, which are mutated in one familial form of AD, may be part of this link. Presenilins are enriched in ER membranes associated with mitochondria and appear to provide a bridge between the two organelles [18]. This link of mitochondria and ER may underline the ADrelated abnormalities that are caused by mutations in presenilin-1.

\section{METABOLIC CHANGES IN AD SUGGEST MITOCHONDRIAL DEFICITS ARE EARLY AND CRITICAL}

\section{Imaging studies of living patients}

Measurements of the cerebral metabolic rate for glucose suggest that metabolic changes precede the onset of histopathological or clinical features. The ability to reliably image glucose metabolism in living people with fluoro-deoxyglucose (FDG) by positron emission tomography (PET) in a non-invasive manner allows temporal studies of living patients in tests of the pathophysiology of AD. The rate of brain glucose utilization predicts whether the patients will progress from mild cognitive impairment (MCI) to AD. Over an 18-month period, patients who went from MCI to AD had lower glucose utilization in the right temporoparietal cortex than those who did not convert [19]. The baseline hippocampal FDG PET predicts decline from normal to AD with $81 \%$ accuracy and from normal to MCI with $71 \%$ accuracy. Greater rates of decline of hippocampal and cortical FDG-PET are found in AD as com- pared to individuals without cognitive decline. Thus, FDG-PET during normal aging predicts cognitive decline in advance of the clinical diagnosis [20]. Other studies demonstrate that glucose utilization in the entorhinal cortex also accurately predicts the conversion from normal to MCI. Among those who declined, the baseline glucose utilization in the entorhinal cortex predicted longitudinal memory and temporal neocortex metabolic reductions. At follow-up, those who declined showed memory impairment and hypometabolism in temporal lobe neocortex and hippocampus. These data suggest that an entorhinal cortex stage of brain involvement can be detected in normal elderly and predicts future cognitive deficits and reductions in brain metabolism [21]. Changes in glucose metabolism may also link the apolipoprotein E $4 \varepsilon$ allele (APOE4) predisposition to the cognitive changes in AD. Among those subjects who declined from MCI to AD, APOE4 carriers show marked reductions in temporal cortex metabolism. Thus, a multiplicity of studies show that glucose metabolism declines in early stages of AD [21].

Changes in glucose metabolism decades before the onset of $\mathrm{AD}$ was demonstrated by examining patients whom have a predisposition due to the presence of APOE4. Patients with AD have abnormally low rates of cerebral glucose metabolism in posterior cingulate, parietal, temporal, and prefrontal cortex. Cognitively normal, late-middle-aged carriers of the APOE4 allele have abnormally low rates of glucose metabolism in the same brain regions as patients with probable AD. The young APOE4 carriers have abnormally low rates of glucose metabolism bilaterally in the posterior cingulate, parietal, temporal, and prefrontal cortex. Thus, carriers of a common AD susceptibility gene have functional brain abnormalities in young adulthood, several decades before the possible onset of dementia [22].

The addition of FDG-PET to a clinical diagnosis provides useful information that can affect the likelihood of detecting AD pathology and may suggest therapeutic options [23]. Recent studies compared three promising biomarkers of AD including CSF amyloid$\beta(\mathrm{A} \beta)$, amyloid PET tracer, and glucose metabolism. The authors concluded that "evidence that FDG-PET abnormalities precede any cognitive symptoms in individuals who later progress to $\mathrm{AD}$ is probably the strongest" [24].

\section{Results with autopsy brain suggest a molecular basis for the decline in metabolism in $A D$}

Measures in living individuals provide a temporal profile of glucose changes but cannot provide as much 


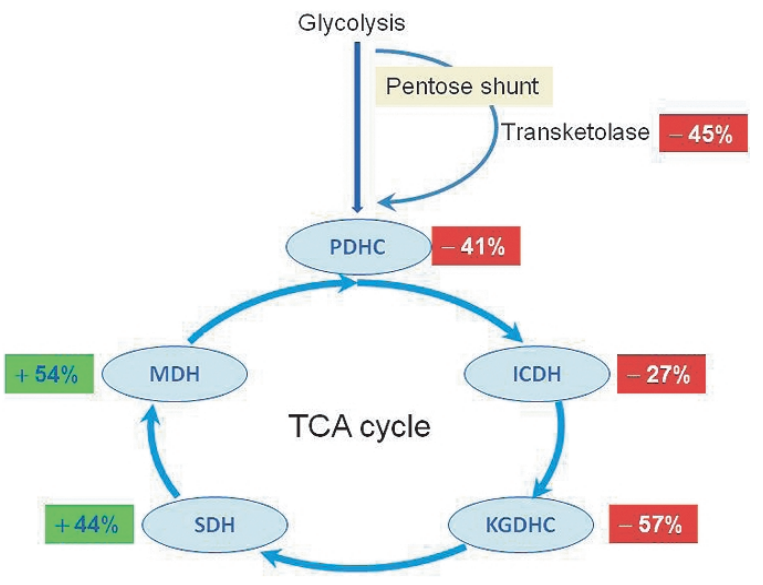

Fig. 1. Critical enzymes of the pentose shunt and the TCA cycle are abnormal in autopsied brains from patients with AD [25,26]. The figure shows the percent change in $\mathrm{AD}$ patients compared to controls. The changes are highly correlated to the clinical dementia rating scores of the patients before they died.

insight into mechanism as studies of autopsy brains. The results suggest that both transcriptional and posttranslational modifications of key metabolic pathways are likely critical.

\section{Protein changes}

Activity measurements of enzymes of metabolic pathways in autopsied brains provide insight into the cause of the decline in glucose utilization with AD. A key enzyme of the pentose phosphate shunt, transketolase, declines $45 \%$ (Fig. 1) [25]. The TCA cycle is the main catabolic converter of glucose to energy in the form of NADH. To determine whether changes in the TCA cycle may underlie the decline in glucose utilization in $\mathrm{AD}$, the activities of the enzymes involved the TCA cycle were determined. The changes in the activities with AD form a discrete pattern. The dehydrogenases that are also decarboxylases are diminished: PDHC $(-41 \%)$, isocitrate dehydrogenase (ICDH) $(-27 \%)$, and KGDHC $(-57 \%)$. On the other hand, the dehydrogenases are increased: succinate dehydrogenase (SDH) (mitochondrial complex II) $(+44 \%)$ and $\mathrm{MDH}(+54 \%)$ (Fig. 1). The highest correlation with the decline in clinical dementia rating scale is with PDHC ( $r=0.77)$ [26].

The protein that shows AD related changes which has been studied in the greatest detail is KGDHC. The activity of KGDHC declines in both genetic and nongenetic forms of $\mathrm{AD}$. In most cases of $\mathrm{AD}$, the protein levels (i.e., immunoreactivity) of KDGHC are not altered, which suggests post-translational modifications cause the reduction in activity [27]. In familial AD patients in which the AD is caused by a mutation in $\mathrm{A} \beta \mathrm{PP}$ processing, the protein levels of KGDHC subunits as detected by the same antibodies suggest reduction in protein levels (i.e., a loss of immunoreactivity [28]). The results are consistent with post-translational inactivation of KGDHC by different ROS in different forms of AD because some ROS alter KGDHC immunoreactivity whereas others do not. The extreme sensitivity of KGDHC to oxidants and the widespread oxidant damage in $\mathrm{AD}$ brains suggests that the deficits in $\mathrm{AD}$ may be oxidant mediated.

Changes in gene expression in autopsy brain support the suggestion that alterations in glucose metabolism are critical in the pathophysiology of $A D$

Transcriptional changes also contribute to the reduction in brain glucose utilization in $\mathrm{AD}$, and these changes may be mediated by oxidants [29]. Gene microarrays of controls and AD reveal that down-regulation of genes involved in protein folding/metabolism/transport, energy metabolism, and signaling pathways accompany $\mathrm{AD}$ [30]. Of the 51 members of the glycolytic, TCA, oxidative phosphorylation, and associated pathways, qPCR indicates that 15 are down-regulated in AD [31]. A genome-wide transcriptomic approach found alterations in the expression of 80 metabolically relevant nuclear genes in posterior cingulate cortex. AD cases have significantly lower expression of $70 \%$ of the nuclear genes encoding subunits of the mitochondrial ETC in posterior cingulate cortex, $65 \%$ of those in the middle temporal gyrus, $61 \%$ of those in hippocampal CA1, $23 \%$ of those in entorhinal cortex, $16 \%$ of those in visual cortex, and $5 \%$ of those in the superior frontal gyrus [32]. mRNA levels of 11 mitochondrial-encoded genes are altered in patients with early and definitive AD. Results reveal down regulation of genes in Complex I, whereas gene expression of Complex III and IV show increases mRNA in patients with early and definitive AD [33]. Genes related to mitochondrial energy metabolism and apoptosis are also upregulated in 2-month old $\mathrm{Tg} 2576$ mice, which bear a double mutation in A $\beta$ PP. The same genes were upregulated at 5 and 18 months [34]. The interpretation of these results and their consequences on brain function is difficult since these diverse changes only reflect steady-state mRNA levels. 
Structural changes in mitochondrial also support their role in the disease process

Morphometric analysis shows that the area of intact mitochondria is significantly decreased in $\mathrm{AD}$, whereas there is no difference between the area of damaged mitochondria in AD or control cases [35].

\section{ANIMAL MODELS OF PLAQUES AND TANGLES SUGGEST METABOLIC DEFICITS OCCUR IN EARLY STAGES OF THE DISEASE PROCESS}

Changes in mitochondria precede other pathological changes even in transgenic mice that are engineered to make plaques and tangles. Mitochondrial A $\beta$ increases at 9 months in the triple Tg-AD mice, whereas mitochondrial function is altered as early as three months of age including the following: decreased respiration, decreased PDHC protein level and activity, increased oxidative stress as manifested by increased $\mathrm{H}_{2} \mathrm{O}_{2}$ production and lipid peroxidation. Even embryonic neurons derived from the hippocampus of the triple transgenic AD mouse model (3xTg-AD) exhibit decreases in mitochondrial respiration and increased glycolysis [36]. In other mouse models of $\mathrm{AD}$, the changes in mitochondrial function also occur before plaque formation. Isolated mitochondria from double Swedish and London mutant $\mathrm{A} \beta \mathrm{PP}$ transgenic mice show pronounced mitochondrial dysfunction including a drop of mitochondrial membrane potential and reduced ATPlevels at 3 months when elevated intracellular, but not extracellular $\mathrm{A} \beta$ deposits are present [37], and there are no reports on presence of mitochondria $\mathrm{A} \beta$ at such an early age.

Whether $\mathrm{A} \beta$ has to be present in the mitochondria to alter mitochondrial function is not clear. $\mathrm{A} \beta$ is a very reactive compound and a multitude of papers show that $\mathrm{A} \beta$ can alter multiple cell and mitochondrial functions when it is added outside the cells or mitochondria, especially at high concentrations (e.g., $10 \mu \mathrm{M}$ ). Even nM concentration of $\mathrm{A} \beta$ added outside cells alters mitochondrial function and oxidase activity [38]. Indeed, $\mathrm{A} \beta$ added to cells inhibits PDHC and KGDHC [39], which are diminished in brains from patients with AD. $\mathrm{A} \beta(10 \mu \mathrm{M})$ also blocks the entry of nuclear encoded proteins into the mitochondria [40] and alters expression of fission proteins. $\mathrm{A} \beta$ can also alter the mitochondrial permeability transition [41]. $\mathrm{A} \beta$ is present in mitochondria in brains from patients with $\mathrm{AD}$ by immunocytochemistry [42] and in transgenic mice.
All of the experiments in transgenic mice that demonstrate mitochondrial $\mathrm{A} \beta$ are done in mice that express high levels of mutant human A $\beta$ PP. For example, the $\mathrm{Tg} 2576$ mouse expresses mutant human A $\beta$ PP 5.56 to 5.76 times the level of endogenous mouse $\mathrm{A} \beta \mathrm{PP}$ [43]. Thus, these mice are designed to make abnormal $\mathrm{A} \beta$ production the initiating cause. Even in these mice, the data are not clear if $\mathrm{A} \beta$ must be present in the mitochondria to get mitochondrial dysfunction. One study demonstrated an increase in $\mathrm{A} \beta$ within mitochondria in the J-20 transgenic mouse strain. The results show a very small amount of $\mathrm{A} \beta$ in mitochondria at 4 months and a marked increase in mitochondrial $\mathrm{A} \beta$ at 8 months. Amyloid plaques occur in this model around 5-7 months [44]. At 8 months, no differences are seen in the mitochondrial $\mathrm{A} \beta$, respiratory control ratio by isolated mitochondria, protein levels of complex I, II, III, and IV or oxygen consumption between control and $\mathrm{J}-20$. At 12 months, mitochondrial $\mathrm{A} \beta$ is quite high and small differences in respiratory control ratio as well as small reductions in complex III or IV are present [42]. However, the measures of mitochondrial function and oxidative stress that usually precede plaque formation by months have not been studied in the J-20 line. In $\operatorname{Tg} 2576$ mice, plaques are not present at two months of age. However, soluble intraneuronal $\mathrm{A} \beta$ deposits are present, but in only very low amounts (about $10 \%$ of those at 12 months) [45]. In addition, increased $\mathrm{H}_{2} \mathrm{O}_{2}$, but no significant increase in carbonyls or cytochrome oxidase occurs at two months of age [45]. In this strain, very few $\mathrm{A} \beta$ deposits occur in 8 month old mice, but by 6 months $\mathrm{A} \beta$ occurs in mitochondria [45]. Earlier studies showed increases in markers of oxidative stress in urine and blood of these mice at 8 months of age [46]. Many $\mathrm{A} \beta$ plaques are present at 17 months but no significant changes in $\mathrm{H}_{2} \mathrm{O}_{2}$ production or cytochrome oxidase are apparent [45]. Thus, the data are consistent that mitochondrial changes precede plaque formation and perhaps the $\mathrm{A} \beta$ accumulation in the mitochondria.

The mechanism for $\mathrm{A} \beta$ entry into mitochondria has been examined. The results from rat mitochondria show that $\mathrm{A} \beta$ is transported into mitochondria via the translocase of the outer membrane (TOM) machinery. The import is independent of the mitochondrial membrane potential [47].

\section{AD models in drosophila also have early mitochondrial changes}

Expression of wild-type or arctic form of $\mathrm{A} \beta$ in a small group of neurons in the adult fly allows study of 
both function and structure of both axon and presynaptic terminals. Depletion of presynaptic mitochondria is the earliest detected phenotype. Diminished axonal transport of mitochondria, accumulation of $\mathrm{A} \beta$ intracellularly, decreased synaptic vesicles, increased large vacuoles, and elevated synaptic fatigue follow. The results suggest early depletion of presynaptic and axonal mitochondria, which lead to other presynaptic deficits and behavioral deficits [48]. The loss of mitochondria at the synapse may be due to reduced transport of mitochondria down the axon. In the $\mathrm{A} \beta_{42}$ fly brain, mitochondria are reduced in axons and dendrites, and accumulate in the somata without severe mitochondrial damage or neurodegeneration. The organization of microtubule or global axonal transport is not significantly altered at this stage [49]. Thus, even in flies engineered to make more $\mathrm{A} \beta$, the mitochondrial changes are very early.

\section{OXIDATIVE STRESS IS AN EARLY EVENT IN AD}

\section{AD patients}

Oxidative stress appears to be an early change in AD. Although markers of oxidative stress cannot be measured in vivo in brain, measures of oxidative stress can be found in urine and occur at very early stages of AD. Isoprostanes are significantly higher in cerebrospinal fluid, plasma, and urine of subjects with MCI and AD compared with cognitively normal elderly subjects [50], suggesting these are early events in AD.

Elevations of markers of ROS damage to proteins, nucleic acids, carbohydrates, and lipids in autopsy brains from AD patients are well-documented [5155]. Oxidative damage in $\mathrm{AD}$ brain is more pervasive than plaques and tangles [56]. Significant increases of an oxidized nucleoside derived from RNA, 8hydroxyguanosine, oxidized amino acids, and nitrotyrosine occur in vulnerable neurons of patients with AD [57,58]. To determine whether oxidative damage is an early- or end-stage event in the process of neurodegeneration, the relationship between neuronal 8hydroxyguanosine and nitrotyrosine and histological and clinical variables (i.e., A $\beta$ plaques, neurofibrillary tangles, duration of dementia, and APOE4 genotype) was determined. The results suggest oxidative damage is quantitatively greatest early in the disease and declines with disease progression. Increases in $\mathrm{A} \beta$ deposition are associated with decreased oxidative damage.
These relationships are more significant in patients with APOE4. Neurons with tangles show a $40 \%-56 \%$ decrease in relative 8-hydroxyguanosine levels compared with neurons free of tangles. The results suggest that increased oxidative damage is an early event in AD that decreases with disease progression and lesion formation [59].

\section{Animal models}

Metabolic changes/oxidative stress occur in early stages of the disease in animals that model various aspects of AD. Reduction in the metabolic enzymes that are diminished in AD brains increases oxidative stress. For example, TD in mice or rats leads to early reductions in the activity of the thiamine dependent enzymes that are diminished in AD. These include enzymes that catalyze key steps in the pentose shunt (transketolase), entry of carbon into the TCA cycle (PDHC) and of the TCA cycle (KGDHC). The reduction in the activities of these enzymes lead to increased oxidative stress in a manner that mimics several aspects of the oxidative stress observed in AD including hydroxynoneal, nitrotyrosine, redox active iron, microglia activation, and increased heme oxygenase [60]. More recent studies show that a reduction in one of the three subunits of KGDHC and PDHC decrease KGDHC and PDHC activities by one half and increases common markers of oxidative stress [11].

Most animal models that are intended to mimic AD are designed to produce plaques or tangles. For example, the Tg2576 mouse express mutant human $\mathrm{A} \beta \mathrm{PP}$ 5.56 to 5.76 times the level of endogenous mouse $\mathrm{A} \beta \mathrm{PP}[43]$. Even in these models, the oxidative stress is an early abnormality. Isoprostanes are specific and sensitive markers of in vivo lipid peroxidation. To determine whether $\mathrm{A} \beta$ deposition in vivo is associated with increased lipid peroxidation, the isoprostane levels were determined in the Tg2576 transgenic mouse model of plaque formation. Levels of urinary isoprostanes are higher in $\mathrm{Tg} 2576$ than in wild type animals as early as 8 months of age and remain high. A similar pattern occurs in plasma, cerebral cortex, and hippocampus. In contrast, a surge of $\mathrm{A} \beta$ levels as well as $\mathrm{A} \beta$ deposits in $\mathrm{Tg} 2576$ mouse brains occurs at 12 months of age [46]. Mitochondrial dysfunction in the 3xTg-AD mouse model, which has mutations leading to plaques and tangles, is also associated with higher levels of ROS [37].

$3 \mathrm{xTg}$ mice with the human transgenes $\mathrm{A} \beta \mathrm{PP}(\mathrm{Swe})$, PS1(M146V), and tau(P301L) also show early oxida- 
tive deficits. At four months, these mice show cognitive deficits and intracellular amyloid oligomers, and at six months hyperphosphorylated tau and extracellular amyloid deposits appear. In striking contrast, glutathione is lower in the $3 \times \mathrm{Tg}$ neurons beginning at one month and continues to be low at 2, 4, and 6 months. $\mathrm{NAD}(\mathrm{P}) \mathrm{H}$ levels are low at 1 month and become lower at 4, 6, and 8 months. Although levels of 8-hydroxyguanine per cell do not increase until six months, cytochrome $\mathrm{C}$ immunoreactivity in mitochondria decreases at 4 and 6 months [61]. A proteomic analysis of this mouse reveals a massive deregulation of 24 proteins, one-third of which are mitochondrial proteins mainly related to complexes I and IV of the oxidative phosphorylation system [62]. Thus, considerable evidence suggests that mitochondrial dysfunction and oxidative stress occur early in animal models of $\mathrm{AD}$.

\section{CHANGES IN CALCIUM IN ENDOPLASMIC RETICULUM AND MITOCHONDRIA IN LIVING CELLS FROM AD PATIENTS}

\footnotetext{
Abnormalities in calcium dynamics have been implicated in AD for many years [63]. Calcium dynamics are difficult to assess in brain. Reductions in calcium uptake were initially shown in fibroblasts from AD patients [64]. Subsequent studies reveal that the bombesin (or bradykinin) releasable calcium stores (BRCS) from the ER are exaggerated in fibroblasts from both sporadic $A D$ patients and patients bearing presenilin- $1 \mathrm{mu}-$ tations [65]. Recent studies show that the changes in BRCS in patients bearing presenilin-1 mutations are because presenilins control calcium leak channels and the AD causing mutations block the leakage [66]. However, in AD fibroblasts bearing A $\beta$ PP mutations, BRCS are diminished [28]. Mitochondrial calcium is also altered in fibroblasts from AD patients [67].

Disturbances of intracellular calcium homeostasis are early events in the pathogenesis of AD in humans and mouse models. In humans, the changes in ER calcium occur in patients' fibroblasts before the patients are symptomatic [68]. Changes occur in transgenic mice long before the pathology. Caffeine evokes a larger response in ER calcium in mutant presenilin-1 knock-in neurons from mice with either a presenilin mutation or in $3 \times \operatorname{Tg}$ mice [69].
}

\section{IMPAIRED METABOLISM/OXIDATIVE STRESS CAN INDUCE AD-LIKE CHANGES IN MITOCHONDRIA AND A $\beta$ PP PROCESSING}

If mitochondrial abnormalities and oxidative stress are upstream effects in $\mathrm{AD}$, then impairing metabolism or oxidants should be able to produce AD like effects. As described below, different forms of mitochondrial impairment or oxidative stress can mimic AD-like changes. However, one particular oxidant does not produce all of the changes. Similarly, one particular antioxidant does not block all of the effects. Thus, stimulating general mitochondrial function or a broad range of antioxidants may be the most effective strategy for treating AD.

\section{In vitro evidence}

Changes in mitochondrial enzymes.

Select oxidants can induce specific changes in metabolic enzymes that are reminiscent of $\mathrm{AD}$ and the changes can be very selective. KGDHC has a central role in metabolism and is among the proteins that are most sensitive to oxidants, and measures in AD brain suggest it has undergone post-translational modification. KGDHC is sensitive to diverse oxidants in a variety of cell free and cellular systems including $\mathrm{H}_{2} \mathrm{O}_{2}$ [7,70-73], hydroxynonenal (HNE) [74], chloroamine [70], sodium hypochlorite [70], t-butyl hydroxyperoxide [75], and acrolein [54]. Catecholamines enhance inactivation of the E3 subunit by the copper Fenton system [76]. Knockout of SOD2 in mice increases ROS production and inactivates $\mathrm{E} 1 \mathrm{k}$ of KGDHC [77]. Increases in cellular ROS and diminished $\mathrm{KGDHC}$ are seen following hyperoxia in $\mathrm{CHO}$ cells [78,79], inhibition of respiration in microglia [7], and elevated MAO expression [5]. Oxidant inactivation of KGDHC by NO can mimic changes in nongenetic forms of $\mathrm{AD}$ (i.e., reduced activity with no change in immunoreactivity). On the other hand, peroxynitrite leads to changes reminiscent of those in the brains from the A $\beta$ PP670/671family (i.e., reduced activity and diminished immunoreactivity) [7]. Thus, specific oxidants lead to inactivation of KGDHC by different mechanisms and each reflects $\mathrm{AD}$ with different causes.

Oxidants can also lead to the selective increase in the other TCA cycle enzymes in a manner that is reminiscent of $\mathrm{AD}$ brain. For examples, in cells in which $\mathrm{KGDHC}$ is compromised, $\mathrm{H}_{2} \mathrm{O}_{2}$ increases both message and protein for MDH (Fig. 2) [80]. Activity of $\mathrm{MDH}$ is elevated in AD brains (see Figs 1,2). 


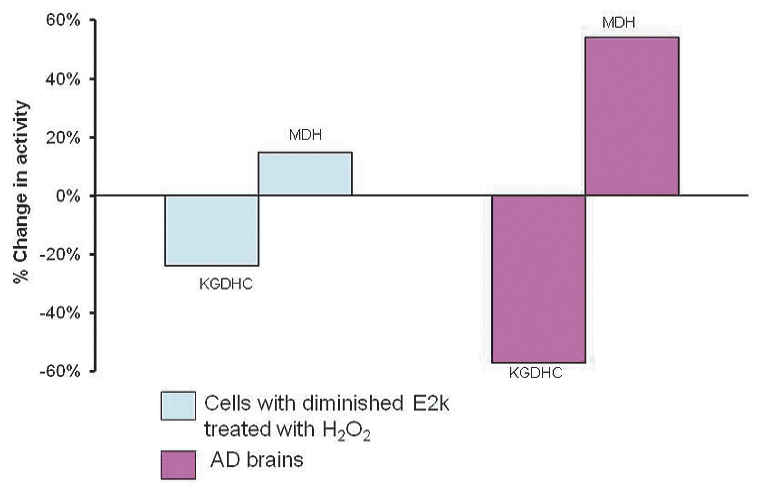

Fig. 2. Oxidant treatment can induce diverse changes in metabolic enzymes that resemble the changes in AD brain [80,136]. Cells with a reduction in one of the three subunits of $\mathrm{KGDHC}(\mathrm{E} 2 \mathrm{k})$ were treated with $\mathrm{H}_{2} \mathrm{O}_{2}$ (see the left half of the figure). KGDHC activity declined while MDH activity increased, which is reminiscent of what happens in AD brains (right half of the figure). Message levels show a similar response to oxidants.

\section{Changes in ER calcium}

The molecular basis of the changes in BRCS from the ER is well established for cells from patients bearing presenilin-1 mutations (see above). The cause of the changes in other patients (i.e., the vast majority) is not established. The observations that select oxidants can induce these alterations suggest they may be causative in the majority of $\mathrm{AD}$ patients, which do not bear presenilin-1 mutations (Fig. 3A). Different oxidants selectively induced various ROS in distinct patterns and selectively modify BRCS [16]. Of the several oxidants tested, tert-butyl-hydroxyperoxide is the most specific for exaggerating BRCS (i.e., a change reminiscent of those in patients bearing presenilin-1 mutations). By contrast, hypoxanthine/xanthine oxidase diminishes BRCS, which is reminiscent of the changes that occur in fibroblasts from patients bearing A $\beta$ PP670/671 mutations [28]. On the other hand, NO did not alter BRCS. Thus, these results are consistent with the hypothesis that abnormalities in selective cellular ROS cause AD-related changes in intracellular calcium regulation [16].

\section{A $\beta$ production and plaque formation}

Interference with energy metabolism and/or oxidative stress alters $\mathrm{A} \beta \mathrm{PP}$ processing and $\mathrm{A} \beta$ production. Induction of oxidative stress by multiple approaches increases $\mathrm{A} \beta$ production and plaque formation. The major enzyme that increases $\mathrm{A} \beta$ from $\mathrm{A} \beta \mathrm{PP}$ is $\beta$ secretase (BACE1). Energy deprivation induces phosphorylation of the translation initiation factor eIF $2 \alpha$, which in turn increases the translation of BACE1 [81].
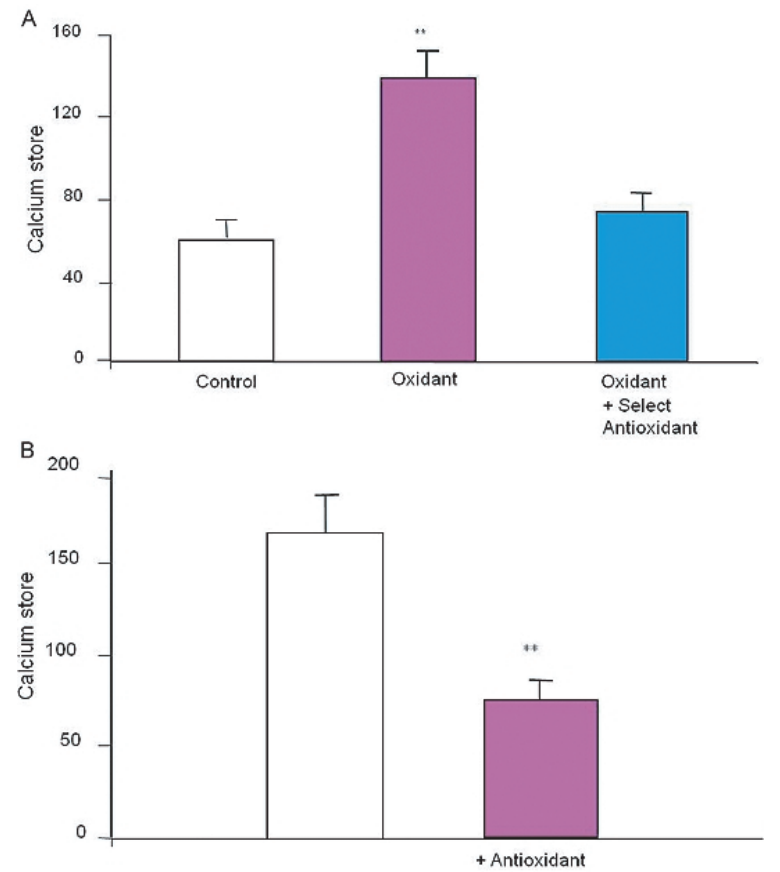

Fig. 3. Select oxidants produce changes in ER calcium in control fibroblasts that are reminiscent of those that occur in cells from AD patients [16]. A variety of oxidants were screened for their ability to increase ER calcium in fibroblasts from controls. Select oxidants increase ER calcium. Select antioxidants could block the oxidant induced change in ER calcium (Fig. 3A). The same antioxidant brought the exaggerated ER calcium in fibroblasts from $\mathrm{AD}$ patients back to control values (Fig. 3B).

In cultured cells, inhibition of ETC by sodium azide or uncoupling of the ETC by the mitochondrial uncoupler carbonyl cyanide m-chlorophenylhydrazone increases amyloidogenic fragments [82]. Pro-oxidant stimuli significantly increase generation of HNE, which increases production of BACE protein [83]. The stimulation of BACE expression by oxidative stress involves the c-jun N-terminal kinase/c-jun pathway [84]. $\mathrm{H}_{2} \mathrm{O}_{2}$ significantly increases BACE1 promoter activity, facilitates $\beta$-secretase activity and $\mathrm{A} \beta$ generation. As emphasized previously, oxidants will also decrease KGDHC and increase ER calcium stores in a manner that is reminiscent of cells from AD patients. Thus, upregulation of BACE1 transcription by oxidative stress may contribute to the pathogenesis of $\mathrm{AD}$ [85].

\section{Mitochondrial fission and fusion}

Mitochondrial fission and fusion may be critical to the pathophysiology of AD. Proteins associated with fusion and fission are reduced (i.e., Drp1, OPA1, Mfn1, and Mfn2) or increased (Fis1) in AD. Manipulations of mitochondrial fission and fusion proteins in neuronal 
cells to mimic their expression changes in AD cause AD-like changes in mitochondrial fission and fusion. Oligomeric $\mathrm{A} \beta$ causes $\mathrm{AD}-$ like changes in mitochondrial fragmentation and reduces mitochondrial density in neuronal processes. Oligomeric $\mathrm{A} \beta$ induces synaptic change (i.e., loss of dendritic spine and postsynaptic density proteins) that correlates with abnormal mitochondrial distribution. Dynamin-like protein 1 (DLP1) is a regulator of mitochondrial fission and distribution. DLP1 overexpression prevents oligomeric $\mathrm{A} \beta$-induced synaptic loss [86]. NO produces mitochondrial fission, in part via S-nitrosylation of dynamin-related protein 1 (Drp1) (SNO-Drp1). Preventing nitrosylation of Drp1 by cysteine mutation abrogates these neurotoxic events. SNO-Drp1 is increased in brains of AD patients. Thus, nitrosylation of Drp 1 may contribute to the pathogenesis of AD [87]. More than $80 \%$ M17 cells overexpressing $\mathrm{A} \beta$ PPswe mutant ( $\mathrm{A} \beta \mathrm{PPswe} \mathrm{M} 17$ cells) display alterations in mitochondrial morphology and distribution. A $\beta$ PP elevated ROS levels, decreased mitochondrial membrane potential, reduced ATP production, and also caused differentiation deficiency upon retinoic acid treatment. Levels of DLP1 and OPA1 are significantly decreased whereas levels of Fis1 are significantly increased in $\mathrm{A} \beta \mathrm{PP} w \mathrm{t}$ and $\mathrm{A} \beta \mathrm{PP}$ swe. The studies suggest that $\mathrm{A} \beta \mathrm{PP}$, through $\mathrm{A} \beta$ production, causes an imbalance of mitochondrial fission/fusion that results in mitochondrial fragmentation and abnormal distribution [88]. Abnormal mitochondrial distribution characterized by elongated mitochondria that accumulated in perinuclear areas in $19.3 \%$ of fibroblasts from non-genetic forms of $\mathrm{AD}$, which was in marked contrast to their normally even cytoplasmic distribution in the majority of human fibroblasts from normal subjects $(>95 \%)$. DLP1 levels are decreased significantly in sporadic AD fibroblasts. Overexpression of wildtype DLP1 in sporadic AD fibroblasts rescued these mitochondrial abnormalities. Antioxidant treatment reversed the AD related changes in DLP1 and in mitochondria suggesting that elevated oxidative stress is likely the potential pathogenic factors that cause DLP1 reduction [89].

\section{In vivo changes}

\section{Amyloidogenic processing of $A \beta P P$}

Interruption of metabolism/mitochondrial function induces oxidative stress and promotes plaque formation. Experimental TD is an established model for reducing the activities of thiamine-dependent enzymes in brain. TD reduces three key enzymes that are di- minished in autopsy brains: transketolase, PDHC, and KGDHC. TD diminishes thiamine-dependent enzymes throughout the brain, but produces a time-dependent selective neuronal loss, glial activation, inflammation, and oxidative abnormalities including elevated HNE in select brain regions. In Tg19959 transgenic mice overexpressing a double mutant form of $\mathrm{A} \beta \mathrm{PP}$, TD exacerbates AD-like pathology and enlarges the area occupied by plaques in cortex, hippocampus, and thalamus by $50 \%, 200 \%$, and $200 \%$, respectively. TD increases BACE1 protein levels by $43 \%$ and $\mathrm{A} \beta$ levels by about three fold. Thus, the induction of mild impairment of oxidative metabolism, oxidative stress, and inflammation by TD alters metabolism of $\mathrm{A} \beta \mathrm{PP}$ and/or $\mathrm{A} \beta$ and promotes accumulation of plaques (Fig. 4) [90]. Much more restricted mitochondrial deficits can also exacerbate plaque formation. The mitochondrial dihydrolipoyl succinyltransferase enzyme (DLST) is a key subunit specific to KGDHC (E2k). Experiments tested whether partial genetic deletion of DLST could accelerate the onset of AD pathogenesis. A transgenic mouse model of amyloid deposition was crossed with DLST $+/-$ mice in which KGDHC activity is reduced by about $40 \%$. DLST deficiency increases $\mathrm{A} \beta$ plaque burden, $\mathrm{A} \beta$ oligomers, and nitrotyrosine levels and accelerates spatial learning and memory deficits [91].

Interruption of metabolism by a variety of other means, including insulin, 2-deoxyglucose, 3nitropropionic acid, and kainic acid, can also promote plaque formation in plaque competent mice. Cerebral BACE-1 rapidly increases approximately $150 \%$ and the enzyme remains elevated for at least seven days. $\mathrm{A} \beta_{1-40}$ levels are increased approximately $200 \%$ of control at 7 days [92]. BACE1 is also induced in association with oxidative stress in the brains of mice subjected to cerebral ischemia/reperfusion [84].

Diminishing antioxidant defense systems also increases plaque formation. Knockout of one allele of manganese superoxide dismutase (MnSOD), a critical antioxidant enzyme, elevates oxidative stress. Crosses of MnSOD deficient mice with plaque competent mice increases brain $\mathrm{A} \beta$ levels and $\mathrm{A} \beta$ plaque burden in $\operatorname{Tg} 19959$ mice. These results indicate that oxidative stress can promote the pathogenesis of AD [93]. Similarly, genetic combination of plaque competent mice with heterozygous SOD2 knockout shows that mitochondrial SOD2 deficiency exacerbates amyloid plaque burden [94].

Many of the effects of oxidants may be mediated by activation of BACE-1, the rate-limiting enzyme for $\mathrm{A} \beta$ production. TD increases BACE-1 [90]. Ener- 

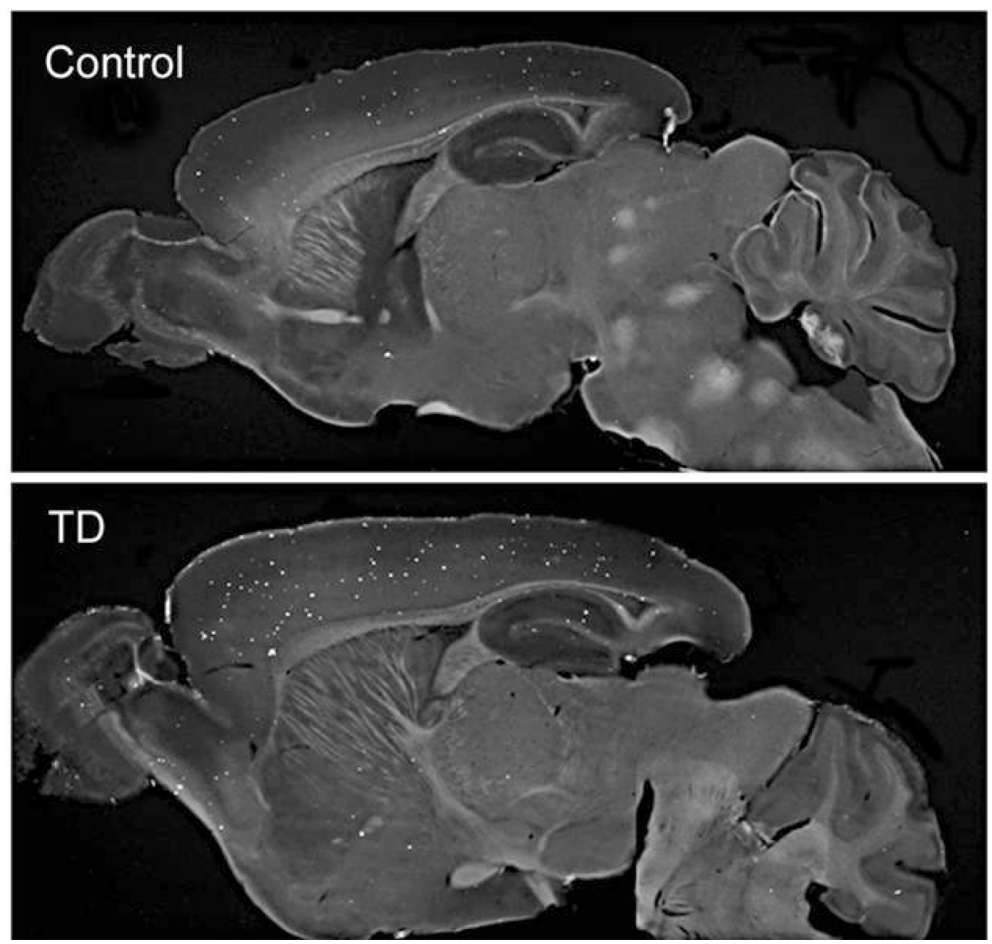

Fig. 4. Mild impairment of oxidative metabolism exaggerates plaque formation in plaque competent mice. TD diminishes the activities of PDHC, KGDHC, and transketolase, which are also diminished in AD. Just ten days of TD leads to a large exacerbation of plaque formation throughout the brain [90].

gy deprivation induces phosphorylation of the translation initiation factor eIF $2 \alpha(\mathrm{eIF} 2 \alpha-\mathrm{P})$, which increases the translation of BACE1. Inhibition of eIF $2 \alpha-\mathrm{P}$ phosphatase increases BACE1 and elevates $\mathrm{A} \beta$ production in primary neurons. Chronic treatment of aged Tg2576 mice with inhibitors of energy metabolism increases levels of eIF $2 \alpha$-P, BACE1, A $\beta$, and amyloid plaques. Preventing eIF $2 \alpha$ phosphorylation blocks the energydeprivation-induced increase in BACE1 [81].

\section{Promotion of cell death by $A \beta P P$ fragments}

Altered $\mathrm{A} \beta \mathrm{PP}$ processing has many implications besides plaque formation. These other actions can occur soon after metabolic interruption and can be driven by diminished metabolism and oxidative stress. Abnormal cleavage of $\mathrm{A} \beta \mathrm{PP}$ leads to production $\mathrm{A} \beta$ and various carboxy terminal fragments of $\mathrm{A} \beta \mathrm{PP}(\mathrm{CTFs})$. Although the precise functions of the A $\beta$ PP CTFs are unknown, they alter membrane currents and calcium homeostasis $[95,96]$, stimulate mitogen activated protein kinase pathways, activate the transcription factor $\mathrm{NF}-\kappa \mathrm{B}$, and elevate inducible nitric oxide synthase (iNOS) [97]. Some A $\beta$ PP CTFs accumulate in the nucleus and bind with Fe65 [97] and CP2 to alter tran- scription [98]. The translocation of CTF to the nucleus has also been implicated in neuronal death in vivo. C-terminal fragments of $\mathrm{A} \beta \mathrm{PP}$ translocate to the nucleus of the neurons destined to delayed degeneration following neurotoxic striatal lesions [99]. Genetic knockouts of $\mathrm{A} \beta \mathrm{PP}$ attenuate microglial activation and enhance neuron survival in substantia nigra compacta after axotomy [100]. Nuclear A $\beta$ PP fragments also play a role in the progressive loss of dopaminergic substantia nigra pars compacta neurons following unilateral medial forebrain bundle transaction [99]. Thus, multiple approaches suggest that nuclear translocation of C-terminal fragments of $\mathrm{A} \beta \mathrm{PP}$ are important in cell death.

Alteration in $\mathrm{A} \beta \mathrm{PP}$ metabolism and nuclear translocation of CTFs of $\mathrm{A} \beta \mathrm{PP}$ have been implicated in neuron death following mild impairment of oxidative metabolism. Neurons that will die on day nine of TD accumulate CTFs of $\mathrm{A} \beta \mathrm{PP}$ in nuclei of within three days of TD. Western blot analysis of nuclear fractions reveals a $61 \%$ increase in CTF12 levels and a $214 \%$ increase in CTF15 levels by TD. These findings demonstrate that changes in $\mathrm{A} \beta \mathrm{PP}$ metabolism occur in early stages of TD, and they may play an important role in TD-induced selective neuronal loss [101]. 


\section{Interference with mitochondrial function/energy metabolism promotes tau phosphorylation}

AD brains contain neurofibrillary tangles that are composed of abnormally hyperphosphorylated tau protein. Disturbed metabolism/oxidative stress can promote tau phosphorylation.

Carbonyl cyanide m-chlorophenylhydrazone, an uncoupler of mitochondrial oxidative phosphorylation, increases by more than 10 -fold the proportion of fibroblasts reacting immunocytochemically with antibodies to paired helical filaments and by 157 -fold the proportion of cells reacting with the Alz-50 monoclonal antibody [102]. Glucose deprivation in cultured hippocampal neurons can result in antigenic alterations similar to those seen in AD neurofibrillary tangles [103]. Mitochondrial SOD2 deficiency exacerbates levels of Ser396 phosphorylated tau. This hyperphosphorylation of tau can be prevented with antioxidant treatment [94]. These observations suggest that the oxidative abnormalities previously described in tissues from patients with AD may contribute to the accumulation of abnormal cytoskeletal materials in this disorder.

Induction of in vivo alterations of glucose metabolism in mice by starvation or intraperitoneal injections of either insulin or deoxyglucose leads to abnormal tau hyperphosphorylation with patterns resembling those in early AD brains [104]. A possible mechanism linking the changes is protein O-GlcNAcylation, a common post-translational modification of nucleocytoplasmic proteins with $\beta$-N-acetyl-glucosamine and a process regulated by glucose metabolism. In AD, OGlcNAcylation is markedly decreased, which negatively correlates with phosphorylation of tau protein. Hyperphosphorylated tau contains 4-fold less O-GlcNAcylation than non-hyperphosphorylated tau, which resembles changes of O-GlcNAcylation and phosphorylation of tau in rodent brains with decreased glucose metabolism induced by fasting. Thus, impaired brain glucose metabolism may lead to abnormal hyperphosphorylation of tau and neurofibrillary degeneration via down regulation of tau O-GlcNAcylation in $\mathrm{AD}$ [105].

Caspase activation provides another link between tangle formation and impaired mitochondrial function. Inhibition of KGDHC leads to release of cytochrome $\mathrm{c}$ and activation of caspase before detectable changes in mitochondrial membrane potentials [106]. Recent studies indicate that caspase activation precedes and leads to tangle formation [107]. Thus, mild impairment of oxidation can lead to caspase activation which may in turn lead to tangle formation.
Thus, the abnormal glucose metabolism that accompanies $\mathrm{AD}$ can be linked to tangle formation. In $\mathrm{AD}$ patients, the decrease in two major brain glucose transporters (GLUT1 and GLUT3) correlate to the increase in the hyperphosphorylation of tau and to the density of neurofibrillary tangles in human brains [108]. Tangles are also present in Wernicke-Korsafoff patients who like AD patients have reductions in PDHC, KGDHC, and transketolase [25].

\section{MITOCHONDRIAL THERAPIES}

The data described above demonstrate that changes in GMO occur early in AD and that that oxidants or impaired metabolism can induce many AD- related abnormalities including changes in metabolic enzymes, ER calcium, A $\beta$ PP processing, and tangle formation that define AD. However, antioxidant therapies of AD have not been successful. This may be because the multifaceted nature of the changes induced by oxidants. Different oxidants may lead to each of the abnormalities. Thus, a therapy must reverse all of the oxidantinduced changes or remove the source of the oxidants. Stabilization of mitochondrial function or reactivation of mitochondrial proteins may achieve this goal.

Understanding the role of KGDHC in neurodegeneration may help develop new therapeutic strategies. Blocking either upstream or downstream effects will likely be beneficial. Diminishing the oxidative stress related to TD protects neurons $[109,110]$. Lipoic acid, an essential cofactor for KGDHC, exerts antioxidant activity through a number of mechanisms involving its thiol-disulfide redox couple or metal binding properties. Lipoic acid supplements have been partially effective in aged rats [111,112], in Parkinson's disease models [112], and in AD [112]. The antioxidant trolox dramatically increases KGDHC activity in cultured cells [72] as does $\mathrm{N}$-acetylcysteine (unpublished results). Lipoamide, lipoic acid, glutathione, and cysteine protect KGDHC from HNE [74]. Inactive KGDHC from $\mathrm{H}_{2} \mathrm{O}_{2}$-treated mitochondria can be reactivated with dithiothreitol or glutaredoxin [74,113]. Activation of metabolic pathways may also bypass KGDHC deficiencies. Activation of PDHC extends life span in mouse models of Huntington's disease [11]. Treatment of AD patients with thiamine or thiamine derivatives [114-116], or bypassing the KGDHC catalyzed step with malate, may be beneficial [117].

Specific oxidants may lead to specific deficits, and reversal of the abnormality may require specific antiox- 
idants. For example, numerous oxidants were tested for their ability to mimic the exaggerated ER calcium that occurs in families bearing presenilin-1 mutations and in sporadic AD. We postulate that in cells from sporadic forms of $\mathrm{AD}$ oxidants induce the change. Tert-butylhydroxyperoxide increases BRCS calcium without altering cytosolic calcium (i.e., a mimic of AD changes) (Fig. 3A) [16]. Furthermore, specific antioxidants can block the oxidant effects on ER calcium (Fig. 3A) [118]. This same antioxidant is able to bring an AD line back to control (Fig. 3B). Thus, for this one variable in a culture dish, an antioxidant can reverse one aspect of AD.

Similarly, several studies using plaques as endpoints have shown beneficial effects in vivo of diminishing oxidative stress. In Tg19959 transgenic AD mice, partial deficiency of the mitochondrial antioxidant enzyme MnSOD exacerbates amyloid pathology. The offspring of Tg19959 mice crossed with MnSOD-overexpressing mice have a $50 \%$ increase in catalase protein levels, a $50 \%$ decrease in levels of oxidized protein, and a $33 \%$ reduction in cortical plaque burden compared to Tg19959 littermates. Thus, MnSOD overexpression lowers plaque formation or increases plaque degradation, and markedly attenuates the phenotype in a transgenic AD mouse model [119]. Immunoreactive iNOS is detected in brains of mice with AD-like disease resulting from transgenic expression of mutant human $\mathrm{A} \beta$ and presenilin-1. $\mathrm{A} \beta \mathrm{PP}-$ or $\mathrm{A} \beta \mathrm{PP} / \mathrm{PS} 1-$ double transgenic mice were bred with iNOS $(+/+)$ or iNOS(-/-) mice. Deficiency of iNOS substantially protects the $\mathrm{AD}$-like mice from premature mortality, cerebral plaque formation, increased $\mathrm{A} \beta$ levels, protein tyrosine nitration, astrocytosis, and microgliosis [120]. Treatment with the antioxidant resveratrol can also diminish plaque formation. Resveratrol, a polyphenol found in red wine, peanuts, soy beans, and pomegranates, possesses a wide range of biological effects. Resveratrol diminishes plaque formation in a region specific manner. The largest reductions in the percent area occupied by plaques occur in medial cortex and hypothalamus. Furthermore, resveratrol reduces brain glutathione by $21 \%$ and increases brain cysteine by $54 \%$. These changes may be mediated by changes in the vasculature since resveratrol is not detectable in brain under these conditions [121].

A difficulty in developing therapies is that multiple targets and multiple oxidants appear to be involved in AD. An understanding of which radicals are altered is critical to the disease, since a single antioxidant may not work. For example, treatment with $\alpha$-tocopherol (vitamin E) prevents HNE activation of BACE in neuronal cell lines [83]. However, Trolox (a close analogue of vitamin E) does not protect KGDHC against oxidant challenge [122]. This lack of effect occurs even though the Trolox quenches the ROS production. The results suggest that KGDHC is more sensitive to oxidants than the probe that was used in these studies. $\alpha$ keto- $\beta$-methyl- $n$-valeric acid diminishes the $\mathrm{H}_{2} \mathrm{O}_{2}$ effects on BRCS, while trolox and dimethyl sulfoxide exaggerate the response. Thus, rather than just blocking the downstream events such as BACE1, efforts should be made to block the oxidants that lead to activation. These same oxidants (or related factors) may lead to the abnormalities in the other facets of the disease.

Another critical question about the use of antioxidants is that some of the responses that are viewed as negative may be protective. For example, treatment of mitochondria with $\mathrm{H}_{2} \mathrm{O}_{2}$ leads to glutathionylation and inactivation of KGDHC. This inactivation diminishes NADH production, which would reduce subsequent free radical production by the ETC. As the $\mathrm{H}_{2} \mathrm{O}_{2}$ declines, $\mathrm{KGDHC}$ is de-glutathionylated and reactivated [123]. By analogy, the reduction of KGDHC activity in $\mathrm{AD}$ brain may be protective in the short term. However, if it is not reversed it can lead to damaging effects including apoptosis. Regardless of that, BACE1 activation may also be protective initially [124]. Thus, diminishing the causative factor of activation seems a better strategy than just blocking activation. For example, HNE, which increases in AD brains and in animal models of AD including TD, inactivates KGDHC and activates BACE1, which may be protective in the short term [125]. Blocking HNE production would reverse two AD -related changes and diminish the need for the protective response.

The multiple facets of AD suggest that treatments which are less specific and act on mitochondria may correct multiple facets of the disease and be more effective than agents that just block one facet of the disease (Fig. 5). Proposed treatments include: creatine [126], lipoic acid [127], CoQ10 (ubiquinone) [128], Idebonone (synthetic analogue of CoQ10), dimebon [129], Mito Q (CoQ10 targeted to mitochondria) [130], SS31 [131], a cocktail of resveratrol, glucose, malate [117], PGC1- $\alpha$ activator [132], stimulation of sirtuins (NAD-dependent histone deacetylase proteins) [133], activators of nrf2/ARE [134], and PPAR $\gamma$ agonists [135]. Thus, a variety of treatments have been proposed to act by protecting mitochondria or stabilizing mitochondrial function to allow the brain to adapt better to disease. 


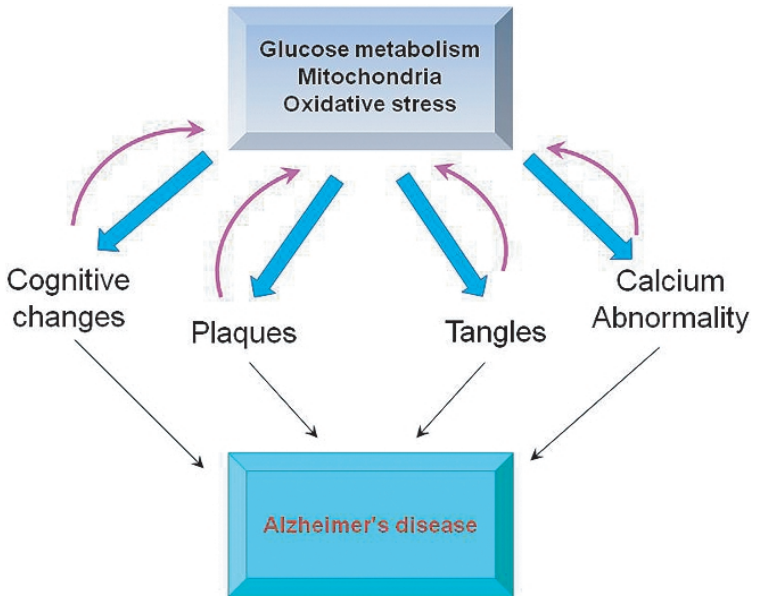

Fig. 5. A mitocentric view of the multifaceted characteristics of AD. Changes in glucose metabolism/mitochondria/oxidative stress (GMO) can be feasibly linked to the cognitive changes, plaques, tangles, and calcium abnormalities, which define AD. Once initiated by changes in GMO, the other deficits can feedback to exaggerate the abnormalities in GMO creating a vicious cycle. This view of AD suggests treatment of the mitochondria/oxidative stress deficit will correct the others whereas treatments targeted at just one facet will fail.

\section{SUMMARY}

GMO appear central to many facets of AD (Fig. 5). In those few families bearing mutations in $\mathrm{A} \beta \mathrm{PP}$ in which the primary gene mutation promotes $\mathrm{A} \beta$ production, it seems likely $\mathrm{A} \beta$ must initiate the change. The majority of animals of $\mathrm{AD}$ model the situation in these few families (i.e., a gene mutation in $\mathrm{A} \beta \mathrm{PP}$ ) leads to overproduction of $\mathrm{A} \beta$. However, in all other cases of $\mathrm{AD}$ (i.e., the vast majority), the change may be initiated and propagated by mitochondrial deficits. Even in the families with gene mutations in $\mathrm{A} \beta \mathrm{PP}$, mitochondria and oxidative stress appear to be integral parts of the pathophysiology and appropriate therapeutic targets. The changes in mitochondrial function can be plausibly linked to the cognitive deficits as well as the senile plaques and neurofibrillary tangles which are the signature of AD. Any screen of therapeutics should not just look at one facet of $\mathrm{AD}$ such as abnormal $\mathrm{A} \beta \mathrm{PP}$ processing, but should test whether the treatment ameliorates multiple facets of the disease.

\section{ACKNOWLEDGMENTS}

This work was supported by NIH AG014930PPG and the Burke Medical Research Institute.

Authors' disclosures available online (http://www.jalz.com/disclosures/view.php?id=403).

\section{REFERENCES}

[1] Joseph JA, Gibson GE (2007) Coupling of neuronal function to oxygen and glucose metabolism through changes in neurotransmitter dynamics as revealed with aging, hypoglycemia and hypoxia. In Handbook of Neurochemistry and Molecular Biology. 3rd edition, Gibson GE, Dienel G, eds. Springer., pp. 297-320.

[2] Brookes PS (2007) Mitochondrial production of oxidants and their role in the regulation of cellular processes In Handbook of Neurochemistry and Molecular Biology. 3rd edition., Gibson GE, Dienel G, eds. Springer., pp. 297-320.

[3] Starkov AA, Fiskum G, Chinopoulos C, Lorenzo BJ, Browne SE, Patel MS, Beal MF (2004) Mitochondrial alpha-ketoglutarate dehydrogenase complex generates reactive oxygen species. J Neurosci $\mathbf{2 4}$, 7779-7788.

[4] Mailloux RJ, Singh R, Brewer G, Auger C, Lemire J, Appanna VD (2009) Alpha-ketoglutarate dehydrogenase and glutamate dehydrogenase work in tandem to modulate the antioxidant alpha-ketoglutarate during oxidative stress in Pseudomonas fluorescens. J Bacteriol 191, 3804-3810.

[5] Kumar MJ, Nicholls DG, Andersen JK (2003) Oxidative alpha-ketoglutarate dehydrogenase inhibition via subtle elevations in monoamine oxidase B levels results in loss of spare respiratory capacity: implications for Parkinson's disease. J Biol Chem 278, 46432-46439.

[6] Bolanos JP, Almeida A (2007) Nitric oxide in regulation of mitochondrial function, respiration, and glycolysis In Handbook of Neurochemistry and Molecular Biology. 3rd edition, Gibson GE, Dienel G, eds. Springer, pp. 487-518.

[7] Park LC, Zhang H, Sheu KF, Calingasan NY, Kristal BS, Lindsay JG, Gibson GE (1999) Metabolic impairment induces oxidative stress, compromises inflammatory responses, and inactivates a key mitochondrial enzyme in microglia. J Neurochem 72, 1948-1958.

[8] Bunik VI, Sievers C (2002) Inactivation of the 2-oxo acid dehydrogenase complexes upon generation of intrinsic radical species. Eur J Biochem 269, 5004-5015.

[9] Huang HM, Ou HC, Chen HL, Hou RC, Jeng KC (2005) Protective effect of alpha-keto-beta-methyl-n-valeric acid on BV-2 microglia under hypoxia or oxidative stress. Ann $N Y$ Acad Sci 1042, 272-278.

[10] Gibson GE, Huang H-M (2004) Mitochondrial enzymes and endoplasmic reticulum calcium stores as targets of oxidative stress in neurodegenerative diseases. J Bioenerg Biomemb 36, 335-340.

[11] Klivenyi P, Starkov AA, Calingasan NY, Gardian G, Browne SE, Yang L, Bubber P, Gibson GE, Patel MS, Beal MF (2004) Mice deficient in dihydrolipoamide dehydrogenase show increased vulnerability to MPTP, malonate and 3nitropropionic acid neurotoxicity. J Neurochem 88, 13521360.

[12] Ke ZJ, Gibson GE (2004) Selective response of various brain cell types during neurodegeneration induced by mild impairment of oxidative metabolism. Neurochem Int 45, 361-369.

[13] Haces ML, Montiel T, Massieu L (2010) Selective vulnerability of brain regions to oxidative stress in a non-coma model of insulin-induced hypoglycemia. Neuroscience 165, 28-38.

[14] Desireddi JR, Farrow KN, Marks JD, Waypa GB, Schumacker PT (2010) Hypoxia increases ROS signaling and cytosolic $\mathrm{Ca} 2+$ in pulmonary artery smooth muscle cells of mouse lungs slices. Antioxid Redox Signal 12, 595-602.

[15] Mattson MP, Zhu H, Yu J, Kindy MS (2000) Presenilin-1 mutation increases neuronal vulnerability to focal ischemia 
in vivo and to hypoxia and glucose deprivation in cell culture: involvement of perturbed calcium homeostasis. J Neurosci 20, 1358-1364.

[16] Huang H-M, Chen H-L, Xu H, Gibson GE (2005) Modification of endoplasmic reticulum $\mathrm{Ca} 2+$ stores by select oxidants produces changes reminiscent of those in cells from patients with Alzheimer disease. Free Radic Biol Med 39, 979-989.

[17] Szabadkai G, Rizzuto R (2007) Mitochondrial endoplasmic reticulum interactions. In Handbook of Neurochemistry and Molecular Biology. 3rd edition, Gibson GE, Dienel G, eds. Springer, pp. 617-640.

[18] Area-Gomez E, de Groof AJ, Boldogh I, Bird TD, Gibson GE, Koehler CM, Yu WH, Duff KE, Yaffe MP, Pon LA, Schon EA (2009) Presenilins are enriched in endoplasmic reticulum membranes associated with mitochondria. Am J Pathol 175, 1810-1816.

[19] Chetelat G, Desgranges B, de la Sayette V, Viader F, Eustache F, Baron J-C (2003) Mild cognitive impairment: Can FDGPET predict who is to rapidly convert to Alzheimer's disease? Neurology 60, 1374-1377.

[20] Mosconi L, De Santi S, Li J, Tsui WH, Li Y, Boppana M, Laska E, Rusinek H, de Leon MJ (2008) Hippocampal hypometabolism predicts cognitive decline from normal aging. Neurobiol Aging 29, 676-692.

[21] de Leon MJ, Convit A, Wolf OT, Tarshish CY, DeSanti S, Rusinek H, Tsui W, Kandil E, Scherer AJ, Roche A, Imossi A, Thorn E, Bobinski M, Caraos C, Lesbre P, Schlyer D, Poirier J, Reisberg B, Fowler J (2001) Prediction of cognitive decline in normal elderly subjects with 2-[(18)F]fluoro-2-deoxyD-glucose/poitron-emission tomography (FDG/PET). Proc Natl Acad Sci U S A 98, 10966-10971.

[22] Reiman EM, Chen K, Alexander GE, Caselli RJ, Bandy D, Osborne D, Saunders AM, Hardy J (2004) Functional brain abnormalities in young adults at genetic risk for late-onset Alzheimer's dementia. Proc Natl Acad Sci U S A 101, 284289.

[23] Jagust W, Reed B, Mungas D, Ellis W, DeCarli C (2007) What does fluorodeoxyglucose PET imaging add to a clinical diagnosis of dementia? Neurology 69, 871-877.

[24] Jack Jr CR, Knopman DS, Jagust WJ, Shaw LM, Aisen PS, Weiner MW, Petersen RC, Trojanowski JQ (2010) Hypothetical model of dynamic biomarkers of the Alzheimer's pathological cascade. Lancet Neurol 9, 119-128.

[25] Gibson GE, Sheu KF, Blass JP, Baker A, Carlson KC, Harding B, Perrino P (1988) Reduced activities of thiaminedependent enzymes in the brains and peripheral tissues of patients with Alzheimer's disease. Arch Neurol 45, 836-840.

[26] Bubber P, Haroutunian V, Fisch G, Blass JP, Gibson GE (2005) Mitochondrial abnormalities in Alzheimer brain: Mechanistic implications. Ann Neurol 57, 695-703.

[27] Gibson GE, Haroutunian V, Zhang H, Park LCH, Shi Q, Lesser M, Mohs RC, Sheu RK-F, Blass JP (2000) Mitochondrial damage in Alzheimer's disease varies with apolipoprotein E genotype. Ann Neurol 48, 297-303.

[28] Gibson GE, Vestling M, Zhang H, Szolosi S, Alkon D, Lannfelt L, Gandy S, Cowburn RF (1997) Abnormalities in Alzheimer's disease fibroblasts bearing the APP670/671 mutation. Neurobiol Aging 18, 573-580.

[29] Shi Q, Gibson GE (2007) Oxidative stress and transcriptional regulation in Alzheimer disease. Alzheimer Dis Assoc Disord 21, 276-291.

[30] Blalock EM, Geddes JW, Chen KC, Porter NM, Markesbery WR, Landfield PW (2004) Incipient Alzheimer's disease:
Microarray correlation analyses reveal major transcriptional and tumor suppressor responses. Proc Natl Acad Sci U S A 101, 2173-2178.

[31] Brooks WM, Lynch PJ, Ingle CC, Hatton A, Emson PC, Faull RLM, Starkey MP (2007) Gene expression profiles of metabolic enzyme transcripts in Alzheimer's disease. Brain Res 1127, 127-135.

[32] Liang WS, Reiman EM, Valla J, Dunckley T, Beach TG, Grover A, Niedzielko TL, Schneider LE, Mastroeni D, Caselli R, Kukull W, Morris JC, Hulette CM, Schmechel D, Rogers J, Stephan DA (2008) Alzheimer's disease is associated with reduced expression of energy metabolism genes in posterior cingulate neurons. Proc Natl Acad Sci U S A 105, 4441-4446.

[33] Manczak M, Park BS, Jung Y, Reddy PH (2004) Differential expression of oxidative phosphorylation genes in patients with Alzheimer's disease: implications for early mitochondrial dysfunction and oxidative damage. Neuromolecular Med 5, 147-162.

[34] Reddy PH, McWeeney S, Park BS, Manczak M, Gutala RV, Partovi D, Jung Y, Yau V, Searles R, Mori M, Quinn J (2004) Gene expression profiles of transcripts in amyloid precursor protein transgenic mice: up-regulation of mitochondrial metabolism and apoptotic genes is an early cellular change in Alzheimer's disease. Hum Mol Genet 13, 1225-1240.

[35] Hirai K, Aliev G, Nunomura A, Fujioka H, Russell RL, Atwood CS, Johnson AB, Kress Y, Vinters HV, Tabaton M, Shimohama S, Cash AD, Siedlak SL, Harris PL, Jones PK, Petersen RB, Perry G, Smith MA (2001) Mitochondrial abnormalities in Alzheimer's disease. J Neurosci 21, 3017-3023.

[36] Yao J, Irwin RW, Zhao L, Nilsen J, Hamilton RT, Brinton RD (2009) Mitochondrial bioenergetic deficit precedes Alzheimer's pathology in female mouse model of Alzheimer's disease. Proc Natl Acad Sci U S A 106, 1467014675.

[37] Hauptmann S, Scherping I, DröPse S, Brandt U, Schulz KL, Jendrach M, Leuner K, Eckert A, Müller WE (2009) Mitochondrial dysfunction: An early event in Alzheimer pathology accumulates with age in AD transgenic mice. Neurobiol Aging 30, 1574-1586.

[38] Shearman MS, Ragan CI, Iversen LL (1994) Inhibition of PC12 cell redox activity is a specific, early indicator of the mechanism of beta-amyloid-mediated cell death. Proc Natl Acad Sci U S A 91, 1470-1474.

[39] Casley CS, Canevari L, Land JM, Clark JB, Sharpe MA (2002) Beta-amyloid inhibits integrated mitochondrial respiration and key enzyme activities. J Neurochem 80, 91-100.

[40] Sirk D, Zhu Z, Wadia JS, Shulyakova N, Phan N, Fong J, Mills LR (2007) Chronic exposure to sub-lethal beta-amyloid $(\mathrm{A} \beta)$ inhibits the import of nuclear-encoded proteins to mitochondria in differentiated PC12 cells. J Neurochem 103, 1989-2003.

[41] Moreira PI, Santos MS, Moreno A, Oliveira C (2001) Amyloid beta-peptide promotes permeability transition pore in brain mitochondria. Biosci Rep 21, 789-800.

[42] Caspersen C, Wang N, Yao J, Sosunov A, Chen X, Lustbader JW, Wei Xu H, Stern D, McKhann G, Yan SD (2005) Mitochondrial $\mathrm{A} \beta$ : a potential focal point for neuronal metabolic dysfunction in Alzheimer's disease. FASEB J 19, 2040-2041.

[43] Hsiao K, Chapman P, Nilsen S, Eckman C, Harigaya Y, Younkin S, Yang F, Cole G (1996) Correlative memory deficits, Abeta elevation, and amyloid plaques in transgenic mice. Science 274, 99-102.

[44] Mucke L, Masliah E, Yu G-Q, Mallory M, Rockenstein EM, Tatsuno Proposed treatments include: creatine [126], 
lipoicbefore they die neuronal expression of Abeta 1-42 in wild-type human amyloid protein precursor transgenic mice: synaptotoxicity without plaque formation. $J$ Neurosci $\mathbf{2 0}$, 4050-4058

[45] Manczak M, Anekonda TS, Henson E, Park BS, Quinn J, Reddy PH (2006) Mitochondria are a direct site of A beta accumulation in Alzheimer's disease neurons: implications for free radical generation and oxidative damage in disease progression. Hum Mol Genet 15, 1437-1449.

[46] Pratico D, Uryu K, Leight S, Trojanoswki JQ, Lee VM (2001) Increased lipid peroxidation precedes amyloid plaque formation in an animal model of Alzheimer amyloidosis. $\mathrm{J} \mathrm{Neu}$ rosci 21, 4183-4187.

[47] Hansson Petersen CA, Alikhani N, Behbahani H, Wiehager B, Pavlov PF, Alafuzoff I, Leinonen V, Ito A, Winblad B, Glaser E, Ankarcrona M (2008) The amyloid beta-peptide is imported into mitochondria via the TOM import machinery and localized to mitochondrial cristae. Proc Natl Acad Sci U $S$ A 105, 13145-13150.

[48] Zhao X-L, Wang W-A, Tan J-X, Huang J-K, Zhang X, Zhang B-Z, Wang Y-H, YangCheng H-Y, Zhu H-L, Sun X-J, Huang F-D (2010) Expression of \{beta\}-amyloid induced age-dependent presynaptic and axonal changes in Drosophila. J Neurosci 30, 1512-1522.

[49] Iijima-Ando K, Hearn SA, Shenton C, Gatt A, Zhao L, Iijima K (2009) Mitochondrial mislocalization underlies Abeta42induced neuronal dysfunction in a Drosophila model of Alzheimer's disease. PLoS ONE 4, e8310.

[50] Pratico D, Clark CM, Liun F, Rokach J, Lee VY, Trojanowski JQ (2002) Increase of brain oxidative stress in mild cognitive impairment: a possible predictor of Alzheimer disease. Arch Neurol 59, 972-976.

[51] Arlt S, Beisiegel U, Kontush A (2002) Lipid peroxidation in neurodegeneration: new insights into Alzheimer's disease. Curr Opin Lipidol 13, 289-294.

[52] Harris ME, Hensley K, Butterfield DA, Leedle RA, Carney JM (1995) Direct evidence of oxidative injury produced by the Alzheimer's beta-amyloid peptide (1-40) in cultured hippocampal neurons. Exp Neurol 131, 193-202.

[53] Lovell MA, Xie C, Gabbita SP, Markesbery WR (2000) Decreased thioredoxin and increased thioredoxin reductase levels in Alzheimer's disease brain. Free Radic Biol Med 28, 418-427.

[54] Pocernich CB, Butterfield DA (2003) Acrolein inhibits NADH-linked mitochondrial enzyme activity: implications for Alzheimer's disease. Neurotox Res 5, 515-520.

[55] Yao Y, Zhukareva V, Sung S, Clark CM, Rokach J, Lee VM, Trojanowski JQ, Pratico D (2003) Enhanced brain levels of 8,12-iso-iPF2alpha-VI differentiate AD from frontotemporal dementia. Neurology 61, 475-478.

[56] Calingasan NY, Uchida K, Gibson GE (1999) Protein-bound acrolein: a novel marker of oxidative stress in Alzheimer's disease. J Neurochem 72, 751-756.

[57] Smith MA, Richey Harris PL, Sayre LM, Beckman JS, Perry G (1997) Widespread peroxynitrite-mediated damage in Alzheimer's disease. J Neurosci 17, 2653-2657.

[58] Nunomura A, Perry G, Pappolla MA, Wade R, Hirai K, Chiba S, Smith MA (1999) RNA oxidation is a prominent feature of vulnerable neurons in Alzheimer's disease. J Neurosci 19, 1959-1964.

[59] Nunomura A, Perry G, Aliev G, Hirai K, Takeda A, Balraj EK, Jones PK, Ghanbari H, Wataya T, Shimohama $S$, Chiba S, Atwood CS, Petersen RB, Smith MA (2001) Ox- idative damage is the earliest event in Alzheimer disease. $J$ Neuropathol Exp Neurol 60, 759-767.

[60] Ke Z-J, Gibson GE Selective response of various brain cell types during neurodegeneration induced by mild impairment of oxidative metabolism. Neurochem Int 45, 361-369.

[61] Brewer GJ, Kunz EA, Parihar MS, Oddo S, LaFerla FM, Torricelli JR (2008) P4-165: 3xTg-AD mouse neurons show early oxidized redox state. Alzheimers Dement 4, T719-T719.

[62] Rhein V, Song X, Wiesner A, Ittner LM, Baysang G, Meier F, Ozmen L, Bluethmann H, Dröse S, Brandt U, Savaskan E, Czech C, Götz J, Eckert A (2009) Amyloid- $\beta$ and tau synergistically impair the oxidative phosphorylation system in triple transgenic Alzheimer's disease mice. Proc Natl Acad Sci U S A 106, 20057-20062.

[63] Gibson GE, Peterson C (1987) Calcium and the aging nervous system. Neurobiol Aging 8, 329-343.

[64] Peterson C, Gibson G, Blass J (1985) Altered calcium uptake in cultured skin fibroblasts from patients with Alzheimer's disease. $N$ Engl J Med 312, 1063-1065.

[65] Ito E, Oka K, Etcheberrigaray R, Nelson TJ, McPhie DL, Tofel-Grehl B, Gibson GE, Alkon DL (1994) Internal Ca2+ mobilization is altered in fibroblasts from patients with Alzheimer disease. Proc Natl Acad Sci U S A 91, 534-538.

[66] Bezprozvanny I (2009) Calcium signaling and neurodegenerative diseases. Trends Mol Med 15, 89-100.

[67] Kumar U, Dunlop DM, Richardson JS (1994) Mitochondria from Alzheimer's fibroblasts show decreased uptake of calcium and increased sensitivity to free radicals. Life Sci 54, 1855-1860.

[68] Etcheberrigaray R, Hirashima N, Nee L, Prince J, Govoni S, Racchi M, Tanzi RE, Alkon DL (1998) Calcium responses in fibroblasts from asymptomatic members of Alzheimer's disease families. Neurobiol Dis $\mathbf{5}, 37-45$.

[69] Smith IF, Hitt B, Green KN, Oddo S, LaFerla FM (2005) Enhanced caffeine-induced $\mathrm{Ca} 2+$ release in the $3 \times \mathrm{xTg}-\mathrm{AD}$ mouse model of Alzheimer's disease. J Neurochem 94, 17111718.

[70] Xu H, Jeitner T, Zhang H, Gibson GE (2001) $\alpha$-Ketoglutarate dehydrogenase and oxidative stress. J Neurochem 78S, 132.

[71] Chinopoulos C, Tretter L, Adam-Vizi V (1999) Depolarization of in situ mitochondria due to hydrogen peroxideinduced oxidative stress in nerve terminals: inhibition of alpha-ketoglutarate dehydrogenase. J Neurochem 73, 220228.

[72] Gibson GE, Zhang H, Sheu KR, Park LC (2000) Differential alterations in antioxidant capacity in cells from Alzheimer patients. Biochim Biophys Acta 1502, 319-329.

[73] Nulton-Persson AC, Starke DW, Mieyal JJ, Szweda LI (2003) Reversible inactivation of alpha-ketoglutarate dehydrogenase in response to alterations in the mitochondrial glutathione status. Biochemistry 42, 4235-4242.

[74] Humphries KM, Szweda LI (1998) Selective inactivation of alpha-ketoglutarate dehydrogenase and pyruvate dehydrogenase: reaction of lipoic acid with 4-hydroxy-2-nonenal. Biochemistry 37, 15835-15841.

[75] Rokutan K, Kawai K, Asada K (1987) Inactivation of 2oxoglutarate dehydrogenase in rat liver mitochondria by its substrate and t-butyl hydroperoxide. J Biochem 101, 415422.

[76] Correa JG, Stoppani AO (1996) Catecholamines enhance dihydrolipoamide dehydrogenase inactivation by the copper Fenton system. Enzyme protection by copper chelators. Free Radic Res 24, 311-322. 
[77] Hinerfeld D, Traini MD, Weinberger RP, Cochran B, Doctrow SR, Harry J, Melov S (2004) Endogenous mitochondrial oxidative stress: neurodegeneration, proteomic analysis, specific respiratory chain defects, and efficacious antioxidant therapy in superoxide dismutase 2 null mice. $J$ Neurochem 88, 657-667.

[78] Pruijn FB, Schoonen WG, Joenje H (1992) Inactivation of mitochondrial metabolism by hyperoxia-induced oxidative stress. Ann N Y Acad Sci 663, 453-455.

[79] Schoonen WG, Wanamarta AH, van der Klei-van Moorsel JM, Jakobs C, Joenje H (1991) Characterization of oxygenresistant Chinese hamster ovary cells. III. Relative resistance of succinate and alpha-ketoglutarate dehydrogenases to hyperoxic inactivation. Free Radic Biol Med 10, 111-118.

[80] Shi Q, Xu H, Kleinman WA, Gibson GE (2008) Novel functions of the alpha-ketoglutarate dehydrogenase complex may mediate diverse oxidant-induced changes in mitochondrial enzymes associated with Alzheimer's disease. Biochim Biophys Acta 1782, 229-238.

[81] O'Connor T, Sadleir KR, Maus E, Velliquette RA, Zhao J, Cole SL, Eimer WA, Hitt B, Bembinster LA, Lammich S, Lichtenthaler SF, Hébert SS, De Strooper B, Haass C, Bennett DA, Vassar R (2008) Phosphorylation of the translation initiation factor eIF2[alpha] increases BACE1 levels and promotes amyloidogenesis. Neuron 60, 988-1009.

[82] Gabuzda D, Busciglio J, Chen LB, Matsudaira P, Yankner BA (1994) Inhibition of energy metabolism alters the processing of amyloid precursor protein and induces a potentially amyloidogenic derivative. J Biol Chem 269, 13623-13628.

[83] Tamagno E, Bardini P, Obbili A, Vitali A, Borghi R, Zaccheo D, Pronzato MA, Danni O, Smith MA, Perry G, Tabaton M (2002) Oxidative stress increases expression and activity of BACE in NT2 neurons. Neurobiol Dis 10, 279-288.

[84] Tamagno E, Guglielmotto M, Aragno M, Borghi R, Autelli R, Giliberto L, Muraca G, Danni O, Zhu X, Smith MA, Perry G, Jo D-G, Mattson MP, Tabaton M (2008) Oxidative stress activates a positive feedback between the gamma- and betasecretase cleavages of the beta-amyloid precursor protein. $J$ Neurochem 104, 683-695.

[85] Tong Y, Zhou W, Fung V, Christensen MA, Qing H, Sun $\mathrm{X}$, Song W (2005) Oxidative stress potentiates BACE1 gene expression and $\mathrm{A} \beta$ generation. J Neural Transm 112, 455469.

[86] Wang X, Su B, Lee H-g, Li X, Perry G, Smith MA, Zhu X (2009) Impaired balance of mitochondrial fission and fusion in Alzheimer's disease. J Neurosci 29, 9090-9103.

[87] Cho D-H, Nakamura T, Fang J, Cieplak P, Godzik A, Gu Z, Lipton SA (2009) S-nitrosylation of Drp1 mediates \{beta\}amyloid-related mitochondrial fission and neuronal injury. Science 324, 102-105.

[88] Wang X, Su B, Siedlak SL, Moreira PI, Fujioka H, Wang Y, Casadesus G, Zhu X (2008) Amyloid-beta overproduction causes abnormal mitochondrial dynamics via differential modulation of mitochondrial fission/fusion proteins. Proc Natl Acad Sci U S A 105, 19318-19323.

[89] Wang X, Su B, Fujioka H, Zhu X (2008) Dynamin-like protein 1 reduction underlies mitochondrial morphology and distribution abnormalities in fibroblasts from sporadic Alzheimer's disease patients. Am J Pathol 173, 470-482.

[90] Karuppagounder SS, Xu H, Shi Q, Chen LH, Pedrini S, Pechman D, Baker H, Beal MF, Gandy SE, Gibson GE (2009) Thiamine deficiency induces oxidative stress and exacerbates the plaque pathology in Alzheimer's mouse model. Neurobiol Aging 30, 1587-1600.
[91] Dumont M, Ho DJ, Calingasan NY, Xu H, Gibson G, Beal MF (2009) Mitochondrial dihydrolipoyl succinyltransferase deficiency accelerates amyloid pathology and memory deficit in a transgenic mouse model of amyloid deposition. Free Radic Biol Med 47, 1019-1027.

[92] Velliquette RA, O'Connor T, Vassar R (2005) Energy inhibition elevates beta-secretase levels and activity and is potentially amyloidogenic in APP transgenic mice: possible early events in Alzheimer's disease pathogenesis. J Neurosci 25 , 10874-10883.

[93] Li F, Calingasan NY, Yu F, Mauck WM, Toidze M, Almeida CG, Takahashi RH, Carlson GA, Flint Beal M, Lin MT, Gouras GK (2004) Increased plaque burden in brains of APP mutant MnSOD heterozygous knockout mice. J Neurochem 89, 1308-1312.

[94] Melov S, Adlard PA, Morten K, Johnson F, Golden TR, Hinerfeld D, Schilling B, Mavros C, Masters CL, Volitakis I, Li QX, Laughton K, Hubbard A, Cherny RA, Gibson B, Bush AI (2007) Mitochondrial oxidative stress causes hyperphosphorylation of tau. PLOS ONE 2, e536.

[95] Turner PR, O'Connor K, Tate WP, Abraham WC (2003) Roles of amyloid precursor protein and its fragments in regulating neural activity, plasticity and memory. Prog Neurobiol 70, 1-32.

[96] Fraser SP, Suh YH, Djamgoz MB (1997) Ionic effects of the Alzheimer's disease beta-amyloid precursor protein and its metabolic fragments. Trends Neurosci 20, 67-72.

[97] Chang KA, Suh YH (2005) Pathophysiological roles of amyloidogenic carboxy-terminal fragments of the beta-amyloid precursor protein in Alzheimer's disease. J Pharmacol Sci 97, 461-471.

[98] Cao X, Sudhof TC (2001) A transcriptionally [correction of transcriptively] active complex of APP with Fe65 and histone acetyltransferase Tip60. Science 293, 115-120.

[99] DeGiorgio LA, Shimizu Y, Chun HS, Kim YS, Sugama S, Son JH, Joh TH, Volpe BT (2002) Amyloid precursor protein gene disruption attenuates degeneration of substantia nigra compacta neurons following axotomy. Brain Res 938, 38-44.

[100] DeGiorgio LA, Shimizu Y, Chun HS, Cho BP, Sugama S, Joh TH, Volpe BT (2002) APP knockout attenuates microglial activation and enhances neuron survival in substantia nigra compacta after axotomy. Glia 38, 174-178.

[101] Karuppagounder S, Xu H, Pechman D, Chen L, DeGiorgio L, Gibson G (2008) Translocation of amyloid precursor protein c-terminal fragment(s) to the nucleus precedes neuronal death due to thiamine deficiency-induced mild impairment of oxidative metabolism. Neurochemical Research 33, 13651372

[102] Blass JP, Baker AC, Ko L-w, Black RS (1990) Induction of Alzheimer antigens by an uncoupler of oxidative phosphorylation. Arch Neurol 47, 864-869.

[103] Cheng B, Mattson MP (1992) Glucose deprivation elicits neurofibrillary tangle-like antigenic changes in hippocampal neurons: Prevention by NGF and bFGF. Exp Neurol 117, 114-123.

[104] Planel E, Miyasaka T, Launey T, Chui D-H, Tanemura K, Sato S, Murayama O, Ishiguro K, Tatebayashi Y, Takashima A (2004) Alterations in glucose metabolism induce hypothermia leading to tau hyperphosphorylation through differential inhibition of kinase and phosphatase activities: implications for Alzheimer's disease. J Neurosci 24, 2401-2411.

[105] Liu F, Shi J, Tanimukai H, Gu J, Gu J, Grundke-Iqbal I, Iqbal K, Gong C-X (2009) Reduced O-GlcNAcylation links lower 
brain glucose metabolism and tau pathology in Alzheimer's disease. Brain 132, 1820-1832.

[106] Huang HM, Ou HC, Xu H, Chen HL, Fowler C, Gibson GE (2003) Inhibition of alpha-ketoglutarate dehydrogenase complex promotes cytochrome c release from mitochondria, caspase-3 activation, and necrotic cell death. J Neurosci Res 74, 309-317.

[107] de Calignon A, Fox LM, Pitstick R, Carlson GA, Bacskai BJ, Spires-Jones TL, Hyman BT (2010) Caspase activation precedes and leads to tangles. Nature 464, 1201-1204.

[108] Liu Y, Liu F, Iqbal K, Grundke-Iqbal I, Gong C-X (2008) Decreased glucose transporters correlate to abnormal hyperphosphorylation of tau in Alzheimer disease. FEBS Lett 582, 359-364.

[109] Shin JT, Barbeito L, MacMillan-Crow LA, Beckman JS, Thompson JA (1996) Acidic fibroblast growth factor enhances peroxynitrite-induced apoptosis in primary murine fibroblasts. Arch Biochem Biophys 335, 32-41.

[110] Spyrou G, Enmark E, Miranda-Vizuete A, Gustafsson J (1997) Cloning and expression of a novel mammalian thioredoxin. J Biol Chem 272, 2936-2941.

[111] Arivazhagan P, Ramanathan K, Panneerselvam C (2001) Effect of DL-alpha-lipoic acid on mitochondrial enzymes in aged rats. Chem Biol Interact 138, 189-198.

[112] Hager K, Marahrens A, Kenklies M, Riederer P, Munch G (2001) Alpha-lipoic acid as a new treatment option for Azheimer type dementia. Arch Gerontol Geriatr 32, 275-282.

[113] Humphries KM, Yoo Y, Szweda LI (1998) Inhibition of NADH-linked mitochondrial respiration by 4-hydroxy-2nonenal. Biochemistry 37, 552-557.

[114] Blass JP, Gleason P, Brush D, DiPonte P, Thaler H (1988) Thiamine and Alzheimer's disease. A pilot study. Arch Neurol 45, 833-835.

[115] Meador K, Loring D, Nichols M, Zamrini E, Rivner M, Posas H, Thompson E, Moore E (1993) Preliminary findings of high-dose thiamine in dementia of Alzheimer's type. J Geriatr Psychiatry Neurol 6, 222-229.

[116] Meador KJ (1994) Treatment strategies for the cognitive deficits of Alzheimer's disease. J S C Med Assoc 90, 543-547.

[117] Blass JP (2008) A new approach to treating Alzheimer's disease. Ann N Y Acad Sci 1147, 122-128.

[118] Huang HM, Zhang H, Ou HC, Chen HL, Gibson GE (2004) alpha-keto-beta-methyl-n-valeric acid diminishes reactive oxygen species and alters endoplasmic reticulum $\mathrm{Ca}(2+)$ stores. Free Radic Biol Med 37, 1779-1789.

[119] Dumont M, Wille E, Stack C, Calingasan NY, Beal MF, Lin MT (2009) Reduction of oxidative stress, amyloid deposition, and memory deficit by manganese superoxide dismutase overexpression in a transgenic mouse model of Alzheimer's disease. FASEB J 23, 2459-2466.

[120] Nathan C, Calingasan N, Nezezon J, Ding A, Lucia MS, La Perle K, Fuortes M, Lin M, Ehrt S, Kwon NS, Chen J, Vodovotz Y, Kipiani K, Beal MF (2005) Protection from Alzheimer's-like disease in the mouse by genetic ablation of inducible nitric oxide synthase. J Exp Med 202, 1163-1169.

[121] Karuppagounder SS, Pinto JT, Xu H, Chen H-L, Beal MF, Gibson GE (2009) Dietary supplementation with resveratrol reduces plaque pathology in a transgenic model of
Alzheimer's disease. Neurochem Int 54, 111-118.

[122] Gibson GE, Zhang H, Xu H, Park LC, Jeitner TM (2002) Oxidative stress increases internal calcium stores and reduces a key mitochondrial enzyme. Biochim Biophys Acta 1586, 177-189.

[123] Applegate MA, Humphries KM, Szweda LI (2008) Reversible inhibition of alpha-ketoglutarate dehydrogenase by hydrogen peroxide: glutathionylation and protection of lipoic acid. Biochemistry 47, 473-478.

[124] Nunomura A, Tamaoki T, Tanaka K, Motohashi N, Nakamura M, Hayashi T, Yamaguchi H, Shimohama S, Lee HG, Zhu X, Smith MA, Perry G (2010) Intraneuronal amyloid beta accumulation and oxidative damage to nucleic acids in Alzheimer disease. Neurobiol Dis 37, 731-737.

[125] Kruman I, Bruce-Keller AJ, Bredesen D, Waeg G, Mattson MP (1997) Evidence that 4-hydroxynonenal mediates oxidative stress-induced neuronal apoptosis. J Neurosci 17, 50895100 .

[126] Chaturvedi RK, Beal MF (2008) Mitochondrial approaches for neuroprotection. Ann N Y Acad Sci 1147, 395-412.

[127] Liu J (2008) The effects and mechanisms of mitochondrial nutrient alpha-lipoic acid on improving age-associated mitochondrial and cognitive dysfunction: an overview. $\mathrm{Neu}$ rochem Res 33, 194-203.

[128] Abdel-Salam OM (2008) Drugs used to treat Parkinson's disease, present status and future directions. CNS Neurol Disord Drug Targets 7, 321-342.

[129] Wu J, Li Q, Bezprozvanny I (2008) Evaluation of Dimebon in cellular model of Huntington's disease. Mol Neurodegener 3, 15 .

[130] Cocheme HM, Kelso GF, James AM, Ross MF, Trnka J, Mahendiran T, Asin-Cayuela J, Blaikie FH, Manas AR, Porteous CM, Adlam VJ, Smith RA, Murphy MP (2007) Mitochondrial targeting of quinones: therapeutic implications. Mitochondrion 7 Suppl, S94-102.

[131] Cho S, Szeto HH, Kim E, Kim H, Tolhurst AT, Pinto JT (2007) A novel cell-permeable antioxidant peptide, SS31, attenuates ischemic brain injury by down-regulating CD36. $J$ Biol Chem 282, 4634-4642.

[132] Flint Beal M (2009) Mitochondrial dysfunction in neurodegenerative diseases and stroke: Neuroprotective strategies. $J$ Neurol Sci 283, 240-240.

[133] Taylor DM, Maxwell MM, Luthi-Carter R, Kazantsev AG (2008) Biological and potential therapeutic roles of sirtuin deacetylases. Cell Mol Life Sci 65, 4000-4018.

[134] Calabrese V, Cornelius C, Mancuso C, Pennisi G, Calafato S, Bellia F, Bates TE, Giuffrida Stella AM, Schapira T, Dinkova Kostova AT, Rizzarelli E (2008) Cellular stress response: a novel target for chemoprevention and nutritional neuroprotection in aging, neurodegenerative disorders and longevity. Neurochem Res 33, 2444-2471.

[135] Landreth G, Jiang Q, Mandrekar S, Heneka M (2008) PPARgamma agonists as therapeutics for the treatment of Alzheimer's disease. Neurotherapeutics 5, 481-489.

[136] Shi Q, Chen HL, Xu H, Gibson GE (2005) Reduction in the E2k subunit of the alpha-ketoglutarate dehydrogenase complex has effects independent of complex activity. $J$ Biol Chem 280, 10888-10896. 